\title{
Water fraction of Sonchus arvensis (Linn.) leaves protects heart upon isoproterenol-induced myocardial infarction in rats and promotes survival of cardiomyocytes in vitro
}

\author{
Neng Fisheri KURNIATI ${ }^{*}$ (D), Elin Yulinah SUKANDAR 1 (D), Rahmayati RUSNEDY 1 (D), \\ Dhyan Kusuma AYUNINGTYAS 1 (D), Nova SULISKA 1 (D), Yasushi FUJIO 2 (iD) \\ 1 Department of Pharmacology-Clinical Pharmacy, School of Pharmacy, Institut Teknologi Bandung, Bandung, \\ Indonesia. \\ 2 Laboratory of Clinical Science and Biomedicine, Graduate School of Pharmaceutical Sciences, Osaka University, \\ Suita, Osaka, Japan. \\ * Corresponding Author. E-mail: nfkurniati@fa.itb.ac.id (N.F.K.); Tel. +62 222504852.
}

Received: 26 March 2018 / Revised: 16 July 2018 / Accepted: 18 July 2018

\begin{abstract}
The study aimed to evaluate the cardioprotective role of Sonchus arvensis (Linn.) leaves in isoproterenol (ISO)-induced myocardial infarction (MI) in Wistar rats and in the survival of cardiomyocytes in vitro upon starvation challenge. Fractions of an ethanolic extract of S. arvensis leaves (100 and $200 \mathrm{mg} / \mathrm{kg}$ bw) were administered orally to Wistar rats (250-300 g) for 14 days. Isoproterenol $85 \mathrm{mg} / \mathrm{kg}$ bw was given at day 13 and 14 . The rats were then sacrificed on the next day. Serum activities of aspartate transferase (AST), alanine transferase (ALT), creatine kinase (CK), creatine kinase-MB (CK-MB) and lactate dehydrogenase (LDH) were measured using standard commercial kits. The protective effect of $S$. arvensis on damaged cardiomyocytes was investigated by examining the cell survival. Furthermore, the Tumor Necrosis Factor-a (TNF-a) serum level of the MI rats was also determined. The results show that pretreatment with n-hexane and ethyl acetate fractions of S. arvensis for a period of 14 days could not attenuate the increase of AST, $\mathrm{ALT}, \mathrm{CK}, \mathrm{CK}-\mathrm{MB}$, and LDH levels upon isoproterenol administration. Moreover, viability of the fractions pretreatedcardiomyocytes showed a cardiotoxic effect. However, pretreatment with the water fraction significantly attenuated the increase of AST, ALT, CK, CK-MB, and LDH levels in isoproterenol-induced MI rats and increased the survival of cardiomyocytes upon starvation challenge. The increase of the TNF-a level upon ISO administration in rats was not observed in the water fraction pre-treatment group. In conclusion, the water fraction of Sonchus arvensis L. leaves at a dose of $100 \mathrm{mg} / \mathrm{kg}$ bw protects the myocardium and exerts cardioprotective effects, probably by inhibiting TNF- $\alpha$ production.
\end{abstract}

KEYWORDS: Sonchus arvensis L.; isoproterenol; myocardial infarction; cardiomyocytes; TNF-a.

\section{INTRODUCTION}

According to WHO, 17.5 million peoples died from CVDs in 2012 [1]. Myocardial infarction (MI), as one of CVDs which causes major death, is characterized by an imbalance of coronary blood supply and demand, resulting in myocardial ischemic injury and cardiomyocytes damage [2]. It is manifested by biochemical alternations accompanied with altered cardiac injury marker enzymes and cardiomyocytes survival [3]. These changes are consequential to the augmented increase in the reactive oxygen species, resulting in oxidative damage to membrane lipids, proteins, carbohydrates and DNA [4]. Therefore, antioxidants may be useful in the treatment of myocardial infarction [5].

In the past decade, there has been an increase in demand for using safe, natural cheap products to reduce the incidence and financial burden of the treatment of myocardial infarction [6], so much interest has focused on complementary and alternative medicine such as herbal medicine in the treatment of myocardial infarction. The search for new agents of herbal remedies may be beneficial in the treatment of this disease.

Flavonoids are a group of natural phenolic compounds which have an activity as antioxidants [7]. It has been reported that daily consumption of flavonoids can reduce the incidence of MI [8]. It has been widely studied that the genus Sonchus is rich in flavonoids and polyphenols. Furthermore, Sonchus arvensis

How to cite this article: Kurniatı NF, Sukandar EY, Rusnedy R, Ayunıngtyas DK, Suliska N, Fujio Y. Water fraction of Sonchus arvensis (Linn.) leaves protects heart upon isoproterenol-induced myocardial infarction in rats and promotes survival of cardiomyocytes in vitro. J Res Pharm. 2019; 23 (2): $242-248$. 
L. is one of the plants that has been reported to have flavonoid, therefore we hypothesized that S. arvensis L. might have cardioprotective effect [9].

Isoproterenol is a potent synthetic catecholamine which induces subendocardial myocardial ischemia and hypoxia. Isoproterenol administration is followed by numerous pathophysiology and biochemical changes such as lipid peroxidation, hyperlipidemia, inflammation, myocyte loss, necrosis, increased calcium overload, and alterations of membrane permeability [10]. Administration of isoproterenol to test animal closely resembles local myocardial infarction-like pathological changes seen in human myocardial infarction [11]. We therefore investigated the effects of the oral administration of the S. arvensis (Linn.) ethanolic extract and its fraction on the cardiac marker and on pro-inflammatory cytokine in isoproterenol-induced myocardial infarction rats. The cardiaoprotective effect was also studied in vitro by measuring cardiomyocytes survival upon nutrient deprivation

\section{RESULTS}

\subsection{Effect of fractions of Sonchus arvensis ethanolic extract on cardiac injury marker}

In our previous study, pretreatment with ethanolic extract of $S$. arvensis $(50,100$ and $200 \mathrm{mg} / \mathrm{kg}$ bw) daily for a period of 14 days attenuated significantly the serum activities of AST, ALT, CK, CK-MB and LDH enzymes compared to ISO alone treated (positive control) rats [12]. However, increase of the dose did not increase its activities. The study was then continued on evaluating $S$. arvensis fraction's activities on cardiac injury marker of ISO-induced MI rats using separated 8 groups.

As can be seen in Table 1, pretreatment with n-hexane and ethyl acetate fraction of $S$. arvensis for a period of 14 days had no effect on serum activities of AST, ALT, CK, CK-MB, and LDH enzymes compared to ISO alone treated rats. However, pretreatment with water fractions of $S$. arvensis at dose of $100 \mathrm{mg} / \mathrm{kg} \mathrm{bw}$ for a period of 14 days showed that water fraction normalized the activities of all cardiac marker studied, indicating cardiac protective effect of water fraction of $S$. arvensis upon ISO administration. The inhibition of water fraction of $S$. arvensis on cardiac marker enzymes activities were higher when the dose of water fraction was increased to $200 \mathrm{mg} / \mathrm{kg}$ bw, suggesting a dose-dependent activity.

Table 1. Effect of fraction of ethanolic extract of Sonchus arvensis (Linn.) on cardiac injury markers in isoproterenol-induced myocardial infarction in rat.

\begin{tabular}{|c|c|c|c|c|c|}
\hline \multirow[b]{2}{*}{ Group } & \multicolumn{5}{|c|}{ Parameters } \\
\hline & $\begin{array}{l}\text { AST } \\
\text { I.U/L }\end{array}$ & $\begin{array}{l}\text { ALT } \\
\text { I.U/L }\end{array}$ & $\begin{array}{c}\mathrm{CK} \\
\mathrm{mg} / \mathrm{dL}\end{array}$ & $\begin{array}{c}\text { CK-MB } \\
\text { I.U/L }\end{array}$ & $\begin{array}{l}\text { LDH } \\
\text { I.U/L }\end{array}$ \\
\hline Negative Control & $130.2 \pm 11.3$ & $102.6 \pm 2.8$ & $0.62 \pm 0.04$ & $179.11 \pm 10.7$ & $357.4 \pm 13.2$ \\
\hline Positive Control & $171.1 \pm 8$ \# & $133 \pm 13.2^{\#}$ & $0.73 \pm 0.01 \#$ & $282.8 \pm 7.6^{\#}$ & $779.8 \pm 22.0^{\#}$ \\
\hline $\begin{array}{l}\text { n-Hexane fraction } \\
100 \mathrm{mg} / \mathrm{kg} \text { bw }\end{array}$ & $193.3 \pm 7.9$ & $174.7 \pm 6.9$ & $0.76 \pm 0.07$ & $753.0 \pm 12.1$ & $1696.7 \pm 13.4$ \\
\hline $\begin{array}{l}\text { n-Hexane fraction } \\
200 \mathrm{mg} / \mathrm{kg} \text { bw }\end{array}$ & $205.7 \pm 3.3$ & $190.0 \pm 6.3$ & $0.94 \pm 0.07$ & $780.0 \pm 3.9$ & $1899.3 \pm 21.8$ \\
\hline $\begin{array}{l}\text { Ethyl acetate } \\
\text { fraction } \\
100 \mathrm{mg} / \mathrm{kg} \mathrm{bw}\end{array}$ & $171.0 \pm 9.1$ & $135.2 \pm 12.4$ & $0.73 \pm 0.02$ & $711.6 \pm 12.8$ & $1221.1 \pm 46.3$ \\
\hline $\begin{array}{l}\text { Ethyl acetate } \\
\text { fraction } \\
200 \mathrm{mg} / \mathrm{kg} \text { bw }\end{array}$ & $155.7 \pm 11.1$ & $117.2 \pm 13.4$ & $0.71 \pm 0.03$ & $297.9 \pm 9.6$ & $797.8 \pm 49.3$ \\
\hline $\begin{array}{l}\text { Water fraction } \\
100 \mathrm{mg} / \mathrm{kg} \text { bw }\end{array}$ & $132.5 \pm 2.4^{*}$ & $103.0 \pm 1.4^{*}$ & $0.62 \pm 0.02$ & $161.9 \pm 4.8^{*}$ & $259.3 \pm 14.4^{*}$ \\
\hline $\begin{array}{l}\text { Water fraction } \\
200 \mathrm{mg} / \mathrm{kg} \text { bw }\end{array}$ & $119.5 \pm 4.8^{*}$ & $81.9 \pm 9.5^{*}$ & $0.30 \pm 0.18^{*}$ & $112.3 \pm 9.4^{*}$ & $221.8 \pm 13.7^{*}$ \\
\hline
\end{tabular}

All values are expressed as Mean \pm SD $(n=3)$. \# means $\mathrm{p}<0.05$ compared to negative control and * means $\mathrm{p}<$ 0.05 compared to positive control. 


\subsection{Effect of fractions of Sonchus arvensis ethanolic extract on cardiomyocyte survival after starvation} challenge

The survival of cardiomyocytes after a starvation-challenge was assessed by cell titer blue assay (Figure 1). It was found that cardiomyocyte nutrient deprivation treatment significantly reduced cell viability to $36.58 \%$ when compared to the normal control. The viability of starved cardiomyocytes cells upon ethanolic extract, n-hexane fraction and ethyl acetate fraction of Sonchus arvensis pretreatment had lower viability than serum-deprived cells (positive control), indicating cardiotoxic effect of the treatment. Only water fraction of Sonchus arvensis could significantly increase viability of cardiomyocytes upon starvation challenge. The effect of water fraction of Sonchus arvensis was similar to leukemia inhibitory factor (LIF) effect.

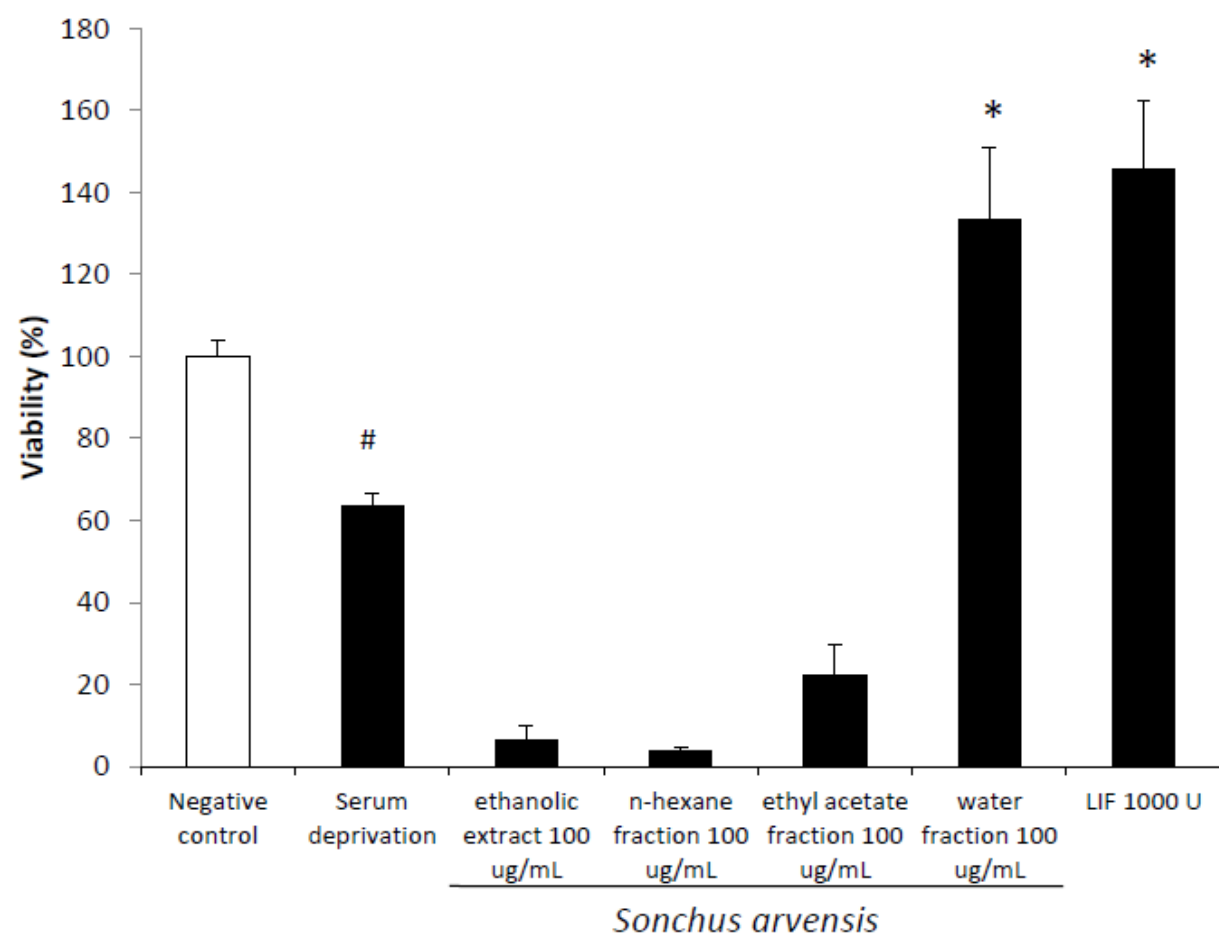

Figure 1. The protection of water fraction of Sonchus arvensis against starvation-induced injury in cardiomyocytes cells. Cells were treated based on their group and starved for $24 \mathrm{~h}$. Cell viability was then measured by cell titer blue assay. The data are expressed as mean \pm SEM. Three replicates were done in each experiment. Three independent experiments were performed. \# indicated the groups with significant difference $(p<0.05)$ when compared to the negative control group. * indicated the groups with significant difference $(\mathrm{p}<0.05)$ when compared to the serum deprivation group. LIF compound was used as survival reference control group.

\subsection{Effect of fractions of Sonchus arvensis ethanolic extract on TNF-a serum level of isoproterenol-} induced myocardial infarction in rats.

Tumor Necrosis Factor- $\alpha$ (TNF- $\alpha$ ), a proinflammatory cytokine, has been reported to induce apoptosis. As TNF receptor is expressed in cardiomyocytes, therefore high level of TNF-a serum may cause cardiomyocytes death [13]. To understand further on mechanism of fractions of $S$. arvensis in protecting the cardiomyocytes, serum level of TNF-a was measured (Figure 2). It was found that ISO administration alone could significantly increase level of TNF-a compared to negative control group suggesting that isoproterenol administration induced inflammation in rats. Similar with previous result, only pretreatment with water fractions of $S$. arvensis could significantly attenuate the increase of TNF-a serum level upon ISO administration. 


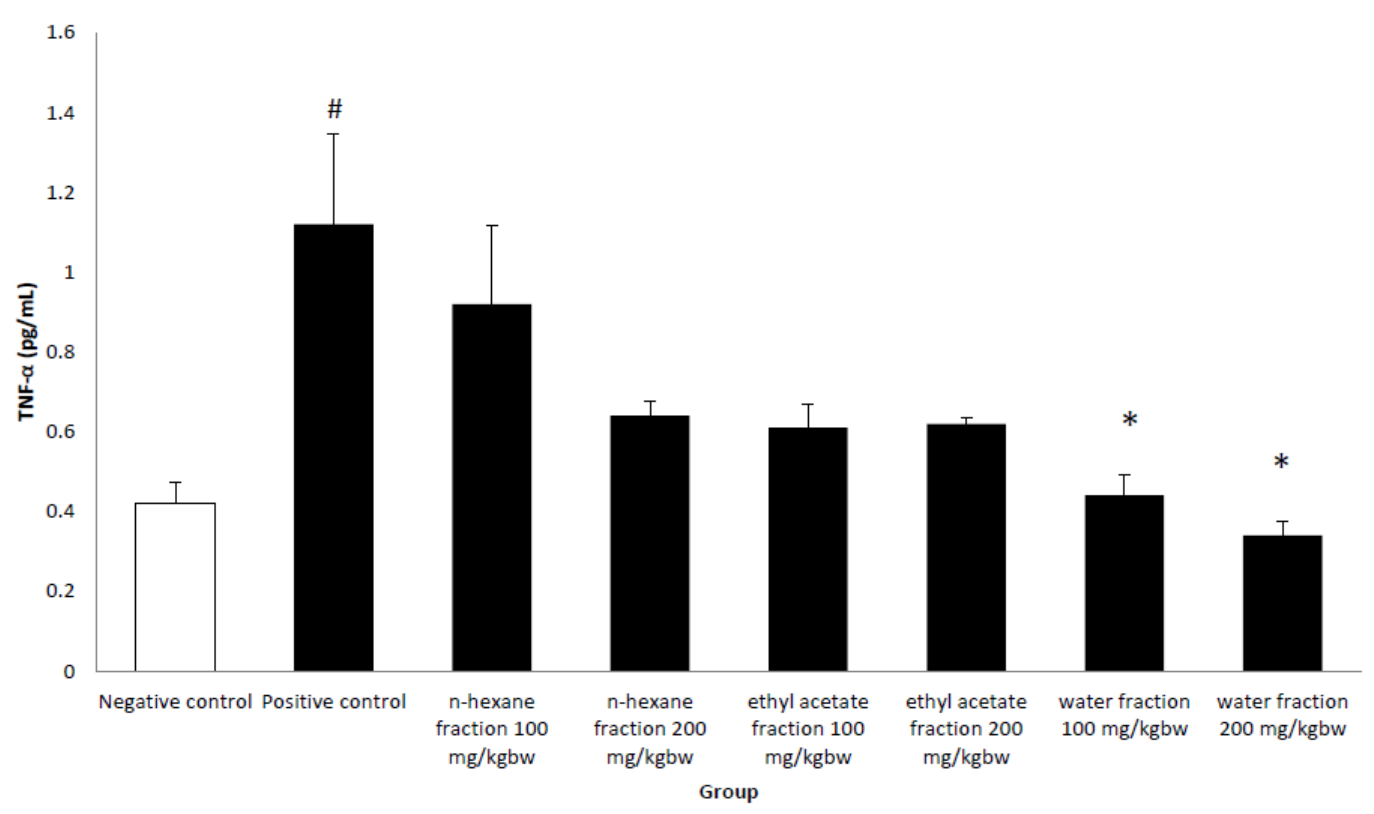

Figure 2. Water fraction of Sonchus arvensis reduced the TNF-a serum level of isoproterenol-induced myocardial infarction in rats. Animals were pre-treated with extract or fractions based on their group for 14 days and then injected with isoproterenol $85 \mathrm{mg} / \mathrm{kg}$ bw intraperitoneally for 2 consecutive days. While positive control group only received isoproterenol intraperitoneally for 2 consecutive days. TNF- $\alpha$ serum level was then measured using ELISA kit. The data are expressed as mean $\pm S D$. $n=3$ /group. \# indicated the groups with significant difference $(p<0.05)$ when compared to the negative control group. * indicated the groups with significant difference $(\mathrm{p}<0.05)$ when compared to the positive control group.

\section{DISCUSSION}

In present study, the effect of ethanolic extract of S. arvensis and its fractions as cardioprotective drug was studied in vivo and in vitro. It was found that only water fraction of $S$. arvensis that attenuated the increase of cardiac injury marker due to isoproterenol administration. In line with in vivo study, result from in vitro study also showed that only water fraction of $S$. arvensis that could protect cardiomyocytes from apoptosis due to starvation challenge. Overall, our results provide information that water fraction of $S$. arvensis has a potency to be developed further as cardioprotective drug.

Myocardium pathophysiological changes were found to be in well accordance with the increase in cardiac biomarker enzyme activities in the serum of MI rats [14]. The present study shows that pretreatment with water fraction of $S$. arvensis significantly prevented the increase of AST, ALT, CK, CK-MB, and LDH level in serum. While other fractions of $S$. arvensis showed the increase of serum AST, ALT, CK, CK-MB, and $\mathrm{LDH}$ level, even higher than positive control group. The similar result was exhibited by examining the viability of starved cardiomyocytes cells which showed higher viability than positive control for water fraction but lower viability for other fractions, indicating cardiotoxic effect of ethanolic extract, n-hexane fraction and ethyl acetate fraction of Sonchus arvensis.

Myocardial cell apoptosis played a key role in heart dysfunction after MI. In the present study, water fraction of $S$. arvensis demonstrated significant anti-apoptotic property in vitro. Pre-treatment with water fraction prevented cell loss induced by apoptosis. As this data is in line with in vivo data and TNF-a level in rat serum was low in water fraction pretreatment group, it suggests that water fraction of $S$. arvensis exhibited protective effects by inhibiting the release of TNF-a, a pro-inflammatory cytokine. However, further study is still needed to prove the concept.

Among six sonchus (Sonchus oleraceus L., Sonchus arvensis L., Sonchus asper (L.) Hill., Sonchus uliginosus M.B., Sonchus brachyotus DC. and Sonchus lingianus Shih) which were investigated by Xia, S. arvensis extract contained the highest antioxidant [15]. Moreover, it is known that flavonoids have antioxidant activity and are soluble in water when it binds to sugar groups [16]. Study by Khan showed that total flavonoids in various fractions of $S$. arvensis are found the highest in methanol fraction and the lowest in n-hexane fraction [17]. Furthermore, previous study by Khan also showed that flavonoids content in S. arvensis is a hydrophilic 
compound, thus the presence is most likely to be found in water fraction. In this study, we also measured flavonoid level in our water fraction of $S$. arvensis and found $10.24 \mathrm{mg}$ flavonoid/g fraction. Therefore, we hypothesized that flavonoids might play a role in cardioprotective activity in water fraction of $S$. arvensis.

This study implies a pharmacological knowledge of a water fraction of S. arvensis Linn. for the protection of heart upon myocardial infarction. The therapeutic use of a water fraction of S. arvensis Linn. can be explored further for other type of cardiovascular disease. This study may act as a pharmacological groundwork of the cardioprotection effect of S. arvensis Linn.; however, one of the limitations of this study is that the cardioprotective effect of the water fraction of $S$. arvensis Linn was only tested on rat and cardiomyocytes. More studies need to be conducted to affirm the cardioprotective potential of $S$. arvensis Linn to humans.

\section{CONCLUSION}

In conclusion, our study firstly demonstrated cardioprotection of water fraction of Sonchus arvensis L. leaves against isoproterenol-induced myocardial infarction in rats and cardiomyocytes survival upon nutrition deprivation. One of probable mechanisms of cardioprotection of water fraction of Sonchus arvensis $\mathrm{L}$. leaves is by reducing the TNF- $\alpha$ production. Our results suggest that water fraction of Sonchus arvensis L. is potential to be developed further as a cardioprotective drug.

\section{MATERIALS AND METHODS}

\subsection{Material}

The ethanol extract of Sonchus arvensis (Linn.) leaves were freshly collected from Baleendah, West Java-Indonesia and determined in Herbarium Bandungense, School of Life Sciences and Technology, Institut Teknologi Bandung (No. 2154/I1.CO2.2/PL/2016). Aspartate Transaminase (AST), Alanine Transaminase (ALT), creatine kinase (CK), creatine kinase-MB (CK-MB), and lactate dehydrogenase (LDH) commercial kits were supplied by Sclavo Diagnostic International, Sovicille, Italy. Tumor necrosis factor-a (TNF-a) enzymelinked immuno sorbent assay (ELISA) kits were supplied by Biolegend, San Diego, CA, USA. Isoproterenol was purchased from Sigma Aldrich Chemical Co., LLC., USA. Moreover, Leukemia Inhibitory Factor (LIF) was purchased from Merck Millipore, Darmstadt, Germany. Other reagents were of commercial analytical grade. All other chemicals and reagents used for study were of analytical grade and were purchased from approved organizations.

\subsection{Extraction and fractionation of Sonchus arvensis (Linn.)}

Crude drug of S. arvensis leaves was extracted by reflux method using ethanol $96 \%$ as a solvent, then evaporated to obtain a thick extract. The crude extract $(50 \mathrm{~g})$ was dispersed in hot water and subjected to sequential liquid-liquid extraction with n-hexane and ethyl acetate to yield fractions. These processes produced n-hexane, ethyl acetate, and water fraction.

\subsection{Experimental procedure}

Twenty four male Wistar rats (weighing 250-300 g) obtained from the Laboratory Animal Center of the School Pharmacy-Institute Technology Bandung used in the study. The animals were maintained under standard laboratory conditions at $25 \pm 5^{\circ} \mathrm{C}$ with a 12-h light/dark cycle.

All animal experimental protocols have been approved by the Institutional Animal Ethics Committee (IAEC) in accordance with the Committee's guidelines for the Objective of Supervision and Control of Animal Experiments (No. 02/KEPHP-ITB/09-2017).

The rats were divided into 8 groups (3 in each group): (1) negative control group, (2) positive control group, (3) n-hexane fraction $100 \mathrm{mg} / \mathrm{kg}$ bw, (4) n-hexane fraction $100 \mathrm{mg} / \mathrm{kg}$ bw, (5) ethyl-acetate fraction $100 \mathrm{mg} / \mathrm{kg}$ bw, (6) ethyl-acetate fraction $200 \mathrm{mg} / \mathrm{kg}$ bw, (7) water fraction $100 \mathrm{mg} / \mathrm{kg} \mathrm{bw}$, and (8) water fraction $200 \mathrm{mg} / \mathrm{kg}$ bw. All test groups were fed with the suspension of fractions of Sonchus arvensis (Linn.) extract by oral gavage once a day for 14 days, along with standard rat chow and water ad libitum. On day 13 and 14, isoproterenol ( $85 \mathrm{mg} / \mathrm{kg}$ bw; i.p) was given to positive control group and test groups [17]. After $24 \mathrm{~h}$ of the last treatment, orbital blood samples were collected from all groups. Blood were collected and centrifuged at $3000 \mathrm{rpm}$ for $10 \mathrm{~min}$ to obtain the serum. The samples were stored at $-80^{\circ} \mathrm{C}$ until used. 


\subsection{Measurement of cardiac injury biomarkers}

Serum was used for estimation of Aspartate Transaminase (AST), Alanine Transaminase (ALT), Creatine Kinase (CK), Creatine Kinase-MB (CK-MB), Lactate Dehydrogenase (LDH) and Tumor Necrosis Factor-a (TNF- $\alpha$ ). The results were expressed as IU/L for AST, ALT, LDH and mg/dL for CK, CK-MB. TNF-a serum was measured using ELISA reader following the corresponding instructions and the result was expressed as $\mathrm{pg} / \mathrm{ml}$.

\subsection{Viability test}

Neonatal rat cardiomyocyte (NRCM) culture was prepared as described previously [18]. NRCM cells were plated on to 96-well plates for cell titer blue assay. Extract or fractions treated cells were under serum deprivation for $24 \mathrm{~h}$, and $10 \mu \mathrm{l}$ CellTiter-Blue ${ }^{\circledR}$ reagent (Promega) was added to each well after extract or fractions addition. Plates were incubated for $3 \mathrm{~h}$ at $37^{\circ} \mathrm{C}$ in a tissue culture incubator, and fluorescence was measured at 560/590 nm using a plate reader. LIF was used as a reference control as it promotes cardiomyocytes survival [19].

\subsection{Statistical analysis}

Significant difference between control and experimental groups was assessed by ANOVA test. $\mathrm{P}<$ 0.05 was considered to be statistically significant. The result of this study was analyzed statistically using SPSS 20 program.

Acknowledgement: This study was supported by the Research, Community Service, and Innovation Programme 2017, Institut Teknologi Bandung (P3MI ITB 2017), Indonesia and by Nishimura Scholarship, Japan.

Author contributions: Concept - N.F.K., E.Y.S., R.R., Y.F.; Design - N.F.K., E.Y.S., R.R. and Y.F.; Supervision - N.F.K., E.Y.S.; Data Collection and Processing - R.R., D.K.A., N.S.; Analysis and Interpretation - N.F.K, E.Y.S, R.R., Y.F.; Literature Search - N.F.K, E.Y.S, R.R., Y.F.; Writing - N.F.K, R.R.; Critical Reviews - N.F.K, E.Y.S, R.R., D.K.A., N.S., Y.F.

Conflict of interest statement: The authors declare that there is no conflict of interest in this research.

\section{REFERENCES}

[1] World Health Organization. Global Status Report of NCD 2014. Geneva: World Health Organization; 2014. (accessed May 15, 2018)

[2] Kloner RA. New observations regarding post-ischemia/reperfusion myocardial swelling. J Am Coll Cardiol. 2015; 65(4): 324-326. [CrossRef]

[3] Hemalatha K, Prince P. Preventive effects of zingerone on altered lipid peroxides and nonenzymatic antioxidants in the circulation of isoproterenol-induced myocardial infarcted rats. J Biochem Mol Toxicol. 2015; 29(2): 63-69. [CrossRef]

[4] Hassan MQ, Akhtar MS, Akhtar M, Ali J, Haque SE, Najmi AK. Edaravone protects rats against oxidative stress and apoptosis in experimentally induced myocardial infarction: Biochemical and ultrastructural evidence. Redox Rep. 2015; 20(6): 275-281. [CrossRef]

[5] Bandyopadhyay D, Chattopadhyay A, Ghosh G, Datta AG. Oxidative stress-induced ischemic heart disease: Protection by antioxidants. Curr Med Chem. 2004; 11(3): 369-387. [CrossRef]

[6] Ho JW, Jie M. Pharmacological activity of cardiovascular agents from herbal medicine. Cardiovasc Hematol Agents Med Chem. 2007; 5(4): 273-277. [CrossRef]

[7] Babu PVA, Liu D.Flavonoids and Cardiovascular Health. In: Watson RR. (Ed). Complementary and Alternative Therapies and the Aging Population. Academic Press, London, 2009, pp. 371-392. [CrossRef]

[8] Hertog MGL, Feskens EJM, Hollman PCH, Katan MB, Kromhout D. Dietary antioxidant flavonoids and risk of coronary heart disease: the Zutphen Elderly Study. Lancet. 1993; 342: 1007-1011. [CrossRef]

[9] Khan RA. Evaluation of flavonoids and diverse antioxidant activities of Sonchus arvensis. Chem Cent J. 2012; 6(1): 126.[CrossRef]

[10] Othman AI, Elkomy MM, El-Missiry MA, Dardor M. Epigallocatechin-3-gallate prevents cardiac apoptosis by modulating the intrinsic apoptotic pathway in isoproterenol-induced myocardial infarction. Eur J Pharmacol. 
2017;794:27-36.[CrossRef]

[11] Wexler BC. Myocardial infarction in young vs old male rats: pathophysiologic changes. Am Heart J. 1978; 96(1): 7080. [CrossRef]

[12] Kurniati NF, Sukandar EY, Pardilah R, Suliska N, Ayuningtyas DK. Cardioprotective potential of ethanol extract of Sonchus arvensis L. Leaves on isoproterenol-induced myocardial infarction in rat. Jurnal Ilmu Kefarmasian Indonesia. 2018; 16(1): 20-24.

[13] Chiong M, Wang ZV, Pedrozo Z, Cao DJ, Troncoso R, Ibacache M, Criollo A, Nemchenko A, Hill JA, Lavandero S. Cardiomyocyte death: mechanisms and translational implications. Cell Death Dis. 2011; 2(12): e244. [CrossRef]

[14] Panda S, Kar A, Biswas S. Preventive effect of Agnucastoside C against isoproterenol-induced myocardial injury. Sci Rep. 2017; 7(1). [CrossRef]

[15] Xia DZ, Yu XF, Zhu ZY, Zou ZD. Antioxidant and antibacterial activity of six edible wild plants (Sonchus spp.) in China. Nat Prod Res. 2011; 25(20): 1893-1901.[CrossRef]

[16] Kumar S, Pandey AK. Chemistry and biological activities of flavonoids: An overview. Sci World J. 2013:1-16. [CrossRef]

[17] Kahn DS, Rona G, Chappel CI. Isoproterenol-induced cardiac necrosis. Ann N Y Acad Sci. 1969;156(1):285293. [CrossRef]

[18] Matsuo R, Morihara H, Mohri T, Murasawa S, Takewaki K, Nakayama H, Maeda M, Fujio Y. The inhibition of Nglycosylation of glycoprotein 130 molecule abolishes STAT3 activation by IL-6 family cytokines in cultured cardiac myocytes. PLos One. 2014; 9(10): e111097. [CrossRef]

[19] Kanda M, Nagai T, Takahashi T, Liu ML, Kondou N, Naito AT, Akazawa H, Sashida G, Iwama A, Komuro I, Kobayashi Y. Leukemia inhibitory factor enhances endogenous cardiomyocyte regeneration after myocardial infarction. Plos One. 2016; 11(5): e0156562. [CrossRef] 